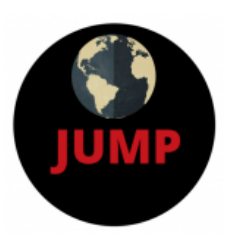

(C) Journal of Underrepresented and Minority Progress

Volume 5, Issue 2 (2022), pp. 182-203 ISSN: 2574-3465 Print/ 2574-3481 Online

http://ojed.org/jump

\title{
Contrasting Challenges of Urban, Suburban, and Rural First-Generation College Students to Improve Retention Programs
}

\author{
Franceska Jones \\ Morgan State University, USA \\ Thomas Eveland \\ Ohio Dominican University, USA \\ Brian Besong \\ St. Francis University, USA
}

\begin{abstract}
The success of first-generation college students (FGCS) is critical to higher education's role in promoting equity and social mobility among underrepresented populations. Although research on FGCS exists, a comprehensive literature review demonstrates an overgeneralization of FGCS characteristics in the presentation of the data. This study reviewed literature from 2000 through 2020 to identify barriers to academic success reported by FGCS in urban, suburban, and rural settings. Findings show varying challenges across settings in three themes: issues arising from academic preparation, issues in persistence, and non-academic influences. The implications of this study guide postsecondary institutions in creating more effective retention programs to address the challenges FGCS faces in a given setting. By illuminating differences in FGCS challenges, this study combats overgeneralizations of a diverse and geographically dispersed population of students.
\end{abstract}

Keywords: academic success, first-generation college students, literature review, persistence, retention 


\section{INTRODUCTION}

Teaching and advising students successfully in U.S. higher education is difficult, made more so by complicating factors like family, lack of academic preparedness, non-academic responsibilities, mental illness or distress, and diminished personal confidence, among others (Bradbury \& Mather, 2009; Clark, 2006; Coffman, 2011; Warburton et al., 2001). Approximately forty percent of United States college students are first-generation (Parks-Yancy \& Cooley, 2018), and research has shown that first-generation college students (FGCS) are disproportionately affected by these barriers that may impede their academic progress and overall success (Coffman, 2011; Pascarella et al., 2004; Pratt et al., 2019; Radford et al., 2015; Radunzel, 2018; Ryan \& Glenn, 2004). Focused attention on available data should help guide educators' attempts to teach and advise FGCS, lest misguided efforts leave this vulnerable student population without the resources it needs.

The COVID-19 pandemic has exacerbated preexisting stressors and has created new challenges such as decreased study time, delayed graduation, loss of employment (and employment opportunities), internships, or job offers, among others (Aucejo et al., 2020). These new challenges affect students from different communities inequitably. Therefore, if student support efforts are to effectively address current student challenges, educators must be aware and devise support programs to address the inequitable impacts of the pandemic (Weissman, 2020). Simplistic reliance on general student research will lead to ineffective strategies, insofar as it implies a one-sized fits all approach to student support.

A large body of research exists concerning FGCS in the United States; the abundance of research riches can make it easy to neglect nuanced findings. Without consideration of specific FGCS challenges in urban, suburban, or rural settings, aggregate data may perpetuate misguided programming by not addressing challenges relevant to students in each setting. Such programming, informed by generalized findings and not addressing the challenges students face in a given setting, could result in misuse of institutions' financial and human resources, lacking adequate support for FGCS, and continued struggle for underrepresented students. Equity demands better.

By reviewing aggregate data in light of significant nuances, our study seeks to draw greater attention to the unique challenges of FGCS in various settings to develop relevant and effective support programming. FGCS are entering the academy with various negative pre-entry attributes making them less likely to succeed (Heinisch, 2017; Pratt et al., 2019; Radunzel, 2018; 
Tieken, 2016). Often these attributes are correlated with background settings, for example rural students may face longer commute times (Peterson et al., 2015) or lower educational aspirations (Tieken, 2016) compared to suburban peers. Colleges and universities unaware of challenges their students face, and relevant responsive support mechanisms, could face decreased retention rates (Tinto, 1988), lower total enrollment, and corresponding revenue issues (O'Keeffe, 2013). Further, universities that seek to fulfill missions centered on access, equity, and community development may struggle to reach strategic goals if FGCS are neglected.

While colleges and universities may face strategic and financial challenges by not supporting FGCS, individual students may face long-term hardships due to lacking support to mitigate challenges associated with FGCS status. Academically unsuccessful FGCS may face increased debt without increased employability in addition to wages lost while attending class (Bowen et al., 2011). Further, the failure of these students may continue to diminish the self-confidence and academic expectations of FGCS by justifying the opinion of unsupportive family and peers (Bradbury \& Mather, 2009). The result of these potential outcomes of each FGCS, when considering the size of this population, could have significant effects on our nation's economic health and do much to demarcate further social classes (Bowen et al., 2005).

\section{PURPOSE OF THE STUDY}

The purpose of this study is to advance the higher education community's cognizance of setting-specific attributes of FGCS toward the end of improving the efficacy of student support programs and retention as they relate to this vulnerable population. First, this review provides a delineation of the general attributes of FGCS in the United States as reported by studies published between 2000 and 2020. Next, the review of selected literature highlights findings providing evidence of differing characteristics and challenges of FGCS in urban, suburban, and rural settings. In so doing, this study illuminates the importance of setting-specific research to more effectively support FGCS with applicable retention and support programs. The literature was reviewed and synthesized under three primary topics: academic preparation, persistence, and non-academic influences.

\section{RESEARCH METHOD}

The formation of this review was guided by Cooper's (1985) Taxonomy of Literature Reviews. The goal of this inductive review was to report, synthesize, and critique research on the study of FGCS. Cooper sought to 
better index and evaluate literature reviews, and his taxonomy served as a valuable framework in developing the design and scope of this review. Specifically, Cooper's framework allows critical characteristics of the review to be determined and the scope and aim to be bounded. Table 1 shows key characteristics as guided by Cooper's work.

\section{Table 1}

Framework of Literature Review as Guided by Cooper's Taxonomy (1985)

\begin{tabular}{cc}
\hline Characteristic & Categories \\
\hline Focus & Research Outcomes \\
Coverage & Central/Pivotal and Representative \\
Goal(s) & Integration and Identification of Central \\
Issues
\end{tabular}

Identifying central findings of FGCS literature that trend throughout the literature was significant in presenting themes, highlighting information gaps, and suggesting future research for setting-specific support of this group of students. This review was not exhaustive but focused on crucial publications that were assumed to present the depth and breadth of quantitative and qualitative research required to thoroughly understand challenges faced by FGCS in aggregate and specific settings. The findings are presented in a conceptual model that delineates macro trends provided by literature. The value of this review of FGCS research is seen in the evaluation and presentation of research, identification of a significant gap in the literature, and recommendation for future work to better inform retention efforts aimed at this population.

Literature published between 2000 and 2020 was sought to correlate research findings with the current makeup of this population. Research before 
2000 and since 2020 certainly improved the understanding and support of FGCS. However, the coverage of this study was non-exhaustive and sought to review literature representative of core works central to the goal of illuminating varying challenges of FGCS across settings in the United States.

The authors of this literature represented many universities and government agencies across the United States. The literature included works published in books, academic journals, government briefs, and dissertations. Many works were augmented with influences from psychosocial development and not only emphasized common FGCS issues but continued to offer remedies to support this group. Direct quotes from FGCS brought aggregate data and quantitative findings into concrete reality and assisted in validating trends through data triangulation. The terms urban, suburban, and rural were not defined as part of this study. The aim of the reviewed literature's original authors was used to stratify FGCS scholarship as studying experiences of FGCS from urban, suburban, and rural settings.

The literature was analyzed for aggregate characteristics and with critical consideration of over-extended generalizability concerning student needs in specific settings. Three key themes became salient when analyzing literature as described above: academic preparation, persistence, and nonacademic influences.

This study examined literature employing many research methods to explore attributes, characteristics, and challenges of FGCS. To fully synthesize the findings, we sought to coalesce results of varying methodologies to appreciate the true depth of the body of literature. Quantitative research provided insights into what positive or negative attributes correlated with FGCS status, and how FGCS performed academically compared to their later-generation peers. Authors of qualitative research focused on discovering root causes of barriers to academic success rather than the quantification of outcomes. Qualitative publications provided narratives of external influences, perceived challenges, financial difficulties, and similar obstacles, often providing a voice for the student through direct quotes. Research of a qualitative nature did much to "tell the story" behind the important outcomes examined in more quantitative studies. The aforementioned three key themes were consistently presented throughout the literature reviewed and guided the analysis of literature below.

\section{LIMITATIONS}

Although steps were taken to ensure this literature review analyzed a robust body of literature and key works in the research of FGCS, it is not without limitations. Two key limitations are worthy of specific discussion. 
One important yet necessary limitation is that this non-exhaustive literature review is bound to a predefined geographical space and only includes literature published between 2000 and 2020. Additionally, the works analyzed as part of this study focused only on the experiences of FGCS in the United States. The exclusion of research outside of the time and location under study limits the global generalization of the findings but was required to ensure the findings inform administrators, researchers, and other stakeholders currently working in colleges and universities across the United States. Further, although studies of the experiences of FGCS in other countries were not part of this review, the findings of this review may inform the design and use of global studies aimed to support FGCS success.

The second key limitation of this study centers on the danger of labeling FGCS as urban, suburban, or rural based on the location of their postsecondary institution and assuming they will neatly fit the characteristics of other FGCS in a given location. For example, suburban post-secondary institutions may have large populations of FGCS from nearby urban and rural settings with vastly different demographic attributes, familial environments, and secondary education experiences. Such generalization is the antithesis of this study's aim. Researchers, policymakers, and other stakeholders should be careful to appreciate the different FGCS in a given location and not to overgeneralize based on an institution's setting.

\section{CHALLENGES OF FIRST-GENERATION COLLEGE STUDENTS}

Given general findings in FGCS research, three thematic challenges are central. First, academic preparation, fostered by secondary curriculum rigor and teacher expectations. Second, persistence, as measured through retention and degree completion rates. Third, non-academic social and familial responsibilities, such as having children or financial responsibilities. Details of thematic challenges surrounding academic preparation, persistence, and non-academic issues are explored below to provide higher education stakeholders with a deeper understanding of how challenges faced by FGCS may vary between settings.

\section{Lacking Academic Preparation}

A recurrent finding in FGCS research is that this population of students is disproportionately likely to be academically underprepared. Universities not sensitive to this heightened need for remediation may experience increased attrition of FGCS, thus affecting retention and revenue (Tinto, 1988); may perpetuate imposter phenomenon (Langford \& Clance, 1993) and disengagement; and may further widen the measured gaps between 
FGCS and economic success. Literature that examines differences in academic preparedness between first-generation and non-first-generation students have focused on metrics such as standardized test scores, grade point average, and type of course work completed in high school (Atherton, 2014). A review of selected literature on FGCS academic preparation is provided below.

In their study of the FGCS success, Warburton, Bugarin, and Nunez (2001) posited that academic preparation at the secondary level is correlated with academic success at post-secondary institutions. Correspondingly, Warburton et al. (2001) found that FGCS were less likely to take a rigorous high-school curriculum, and few took courses transcending basic high-school requirements. Rigorous core courses can provide students with the cognitive strategies necessary for college success (Woods et al., 2018). First-generation college students were reported to be more likely than non-FGCS to take geometry or algebra II as their highest math and less likely to take calculus (Warburton et al., 2001). Woods et al. (2018) argued that a disconnect between the K-12 sector and higher education creates issues defining college readiness. High schools that are not providing necessary rigor, though ostensibly boosting their own graduation rates, place their students at a disadvantage with regards to postsecondary success. Rural K-12 programs, among others, often lack rigorous coursework due inter alia to smaller student populations that make running selective classes financially burdensome (Handwerk et al., 2008; Peterson et al., 2015), among other disparities in access to elements positively correlated with post-secondary success (Byun et al., 2012).

Not all FGCS come from neighborhoods with low performing schools, but typically FGCS are overrepresented in lower-income communities and have made their way through failed educational systems. Students with the FGCS status were less than half as likely as their peers to take college admissions tests, and those that completed these tests were more likely to receive markedly lower scores (Warburton et al., 2001). Additionally, Warburton et al. reported that FGCS commonly need remedial courses, especially when compared to populations whose secondary curricula exceeded the basic high-school requirements. This 2001 study posited that having the status of FGCS was negatively correlated with academic rigor, and the latter was positively correlated with success after matriculation. Warburton et al. (2001) provided great insight into aggregate trends in the academic preparation of FGCS; however, first-person accounts of academic challenges provided valuable depth in understanding individual situations of FGCS. 
In an interview-based study sponsored by the Pell Institute for the Study of Opportunity in Higher Education, Engle, Bermeo, and O'Brien (2006) illustrated concrete examples of lacking academic preparation that Warburton et al. (2001) correlated with diminished academic outcomes. The qualitative format allowed the discussion to move the focus from correlated outcomes to narrated causes. This perspective potentially deepens our understanding of appropriate remedies for FGCS. For example, Warburton et al. (2001) correlated academic struggles with non-rigorous high school coursework completed by FGCS. Engle et al. (2006), through interviews and dialogue, found that opportunities to learn beyond the standard secondary curriculum may be limited for FGCS. Further, the 2006 study posited that lack of encouragement (especially by parents) to enroll in more rigorous secondary curricula may have a causal relationship with a failure to enroll in such curricula. This novel insight suggests that FGCS may have desired, or were at least willing, to be academically prepared for college-level work in their secondary curriculum but may not have had a socially-accepted opportunity to do so. A lack of encouragement to enroll in rigorous secondary curricula also functions to undermine a FGCS's self-perceived academic ability, another recurrent finding in FGCS research and borne out by the qualitative work of Engle et al. (2006). Understanding such insights is paramount to faculty teaching and advising FGCS and to academic support functions' efforts to increase FGCS success in the academy. For FGCS have often been indirectly taught that advanced academic performance is not necessary, expected, or even desirable.

Despite their differing methods, both studies find similar trends of FGCS entering the academy. Similar to Warburton et al. (2001), Engle et al. (2006) and Woods et al. (2018) cited lacking academic rigor as a correlate to FGCS attrition. Engle et al. (2006) discuss detrimental effects low teacher expectations and limited resources in secondary schools have on preparation of FGCS. The pre-attrition nature of the study allowed for gaps between the secondary and post-secondary curricula to be narrated as opposed to simply correlated. Like Warburton et al., Engle et al. reported the importance of rigorous coursework, especially in math, but went further in noting the limited availability of rigorous courses in many secondary districts. This paradoxical relationship perfectly highlights an opportunity to support FGCS through counseling and expanded curricula at the secondary level or planned remediation and counseling at the post-secondary level.

Reid and Moore (2008) further validated many challenges faced by academically underprepared FGCS through their qualitative research, summarizing key findings in keeping with those just mentioned. Reid and 
Moore (2008) reported that students faced challenges in academic coursework and understanding the university culture. For example, one student highlighted that she was not prepared for the freedom of college coursework. The student's comments noted the importance of daily homework, one-onone time with the teacher, regular papers and quizzes, and other regularly assigned learning exercises that are not present in many college courses. Concerning academic preparation, students were not ready for the pedagogical changes that take place when matriculating. These students felt that they lacked preparation in working with laboratories (e.g., dissections) and educational technology. They continued to cite time-management, and study skills as major barriers. While some conversations centered on subject matter preparation (typically in writing and advanced math), the most salient themes in this study were not subject-specific.

Azmitia et al. (2018) provides more evidence of the challenges and resources faced by FGCS as they navigate college and assess the role of educational resiliency. Lacking academic preparedness contributed to feelings of not belonging to the campus atmosphere. This feeling may be amplified by the trend of FGCS to live and work off campus and to take postsecondary coursework merely part rather than full time (Bradbury \& Mather, 2009; Engle et al., 2006). When assessing motivation to continue in college despite not being academically prepared, students' responses illustrate how a college degree has become essential for upward mobility in the United States (Azmitia et al., 2018). Peterson et al.'s (2015) study of rural students in Washington state suggests that educators can develop effective strategies based on this recognized benefit, by promoting potentially lucrative careers in the STEM fields.

Warburton et al. (2001), Engle et al. (2006), Reid and Moore (2008), and Azmitia et al. (2018) did much to deepen the literature on FGCS; however, some limitations in generalizability across urban, suburban, and rural settings are highlighted in a synthesis of some of their findings. For example, although Warburton et al. provided a wealth of general information on FGCS outcomes, the study's applicability to, and correlation with, any given campus will vary since the characteristics of FGCS at a particular campus deviate from national trends. Engle et al. focused on FGCS in Texas. While some findings aligned with the Warburton et al. study, educators should realize that FGCS in urban Houston institutions will have significantly different needs than those in rural west Texas farming communities, for example.

The findings of Reid and Moore (2008) further highlighted contrasting characteristics of FGCS between specific settings. Urban students 
in Reid and Moore cited non-subject matter issues as major challenges. Many FGCS in the study took at least one AP course, and had access to college preparation coursework in their secondary curriculum. This finding varies from the less localized studies reviewed above that cited the absence of opportunities for advanced secondary coursework as a barrier to FGCS success. These examples of differing needs and availability of resources illuminate the need for setting-specific research to inform FGCS retention and success efforts, as well as future research to identify further predictive variables. Academically supporting FGCS cannot stop with remedial coursework and efforts to supplement lacking academic preparation upon enrollment. Once students are more academically prepared and instilled with confidence, continued programming must foster persistence throughout the curriculum.

The findings of Azmitia et al. (2018), although helpful in understanding the motivations for FGCS to persist, focused on the transition to and through college of FGCS at a state university in California. This study did make references to the differences in demographics of FGCS and how that may play a part in the type of support services required but failed to include setting-specific suggestions to the list of recommendations.

\section{Issues in Persistence}

In the United States, 30-50\% of all FGCS leave after their first year (Azmitia et al., 2018). Insufficient academic preparation is not often remediated by well-intended developmental courses and freshman seminars. Deficient understanding of subject matter, poor time-management skills, and underdeveloped study habits of FGCS prove burdensome and are consequently correlated with attrition (Chen \& Carroll, 2005; Clark \& Cundiff, 2011; Ryan \& Glenn, 2004). In addition to the previously mentioned issues, executive functioning skills are underdeveloped in many FGCS (Garriott \& Nisle, 2017). As such, faculty, administrators, and staff are compelled to identify potential barriers faced by FGCS on their campuses and develop applicable, effective programming to improve FGCS persistence. At least in urban settings, effective, localized programs have been correlated with hedging high attrition rates of this group (Roe Clark, 2006). Improving the retention of such a large population will reduce financial losses resulting from decreased tuition revenue and costly yet ineffective retention programs. In the midst of the COVID-19 global pandemic, colleges are crunched for enrollment like never before. Retaining FGCS now more than ever will significantly impact many colleges' and universities' bottom lines. Three informative studies are synthesized below to provide insight into challenges 
surrounding persistence and illustrate varying levels of generalization and scope of FGCS literature. In addition to the three core studies synthesized, more recent studies support the findings presented and more insight into the challenges in persistence for FGCS.

In 2005, Chen and Carroll completed a study for the National Center for Education Statistics (NCES) to identify common barriers FGCS face in meeting their educational goals. In a culminating statement, Chen and Carroll (2005) stated that 43 percent of the FGCS in the cohort studied left without attaining a bachelor's degree. In contrast, only 20 percent of non-FGCS in the same cohort left without earning the same degree (Chen \& Carroll, 2005). Chen and Carroll indicated that FGCS who completed higher-level math courses at the high school level were still not as successful in college as their non-FGCS counterparts. Further, Chen and Carroll reported that even highmath FGCS were more likely than non-FGCS to leave without obtaining a degree and less likely to obtain a bachelor's degree. Their report correlated long-term academic success with credit production and strong academic performance in the first year, both negatively correlated with FGCS status. Further, Chen and Carroll provided that the low first-year GPAs of FGCS are not readily shed at the end of their freshman coursework. By comparison, FGCS reported an overall GPA of 2.6 and non-FGCS reported an overall GPA of 2.9 (Chen \& Carroll, 2005).

Chen and Carroll provide a significant body of aggregate data that sets an appropriate context for further discussion of generally reported issues affecting FGCS persistence. In 2018, Cataldi et al. updated previous research with a closer look at college access, persistence and post-bachelor's outcomes of FGCS. Their updated findings argue that three years after first enrolling, comparatively more FGCS had left post-secondary education without earning a post-secondary credential. While Chen and Carroll (2005) noted key correlations in an outcomes-based study, Darling and Smith (2007) described challenges faced by FGCS concerning factors that are not readily quantified. Darling and Smith noted that challenges faced by students with high-risk factors, including low SES, identifying as a minority, and lacking experience in the academy negatively impact many FGCS. They indicated that minority status, often correlated with FGCS status (Engle et al., 2006), is in turn negatively correlated with success in the academy (Darling \& Scandlyn Smith, 2007). Similarly, low SES is negatively correlated with attendance and success. Darling and Smith posited that the SES of many FGCS may affect academic success by way of financial need. This finding aligns with findings of Bradbury and Mather (2009) showing FGCS' need to work off-campus can be correlated with disengagement (Bradbury \& Mather, 2009), which is 
correlated with attrition (Tinto, 1988). These are ominous correlations as many FGCS reported a low SES, and identified as a minority (Darling \& Smith, 2007; Engle et al., 2006).

Darling and Smith (2007) provided a valuable perspective in discussing psychosocial factors associated with objective measurements provided by Chen and Carroll (2005). The potential overgeneralization of aggregate studies calls into question the applicability of the data in all settings. Chen and Carroll's, and Darling and Smith's review, given its limited scope, stand out in this regard. To provide more detail on the correlation of FGCS status and academic success, we revisited Warburton et al.'s 2001 report published by the NCES.

Pratt et al. (2019) provided an expanded view of potential challenges in persistence for FGCS. FGCS often suffer from a lack of confidence regarding their academic preparation for college and their ability to succeed in the college environment (Pratt et al., 2019). Financial security concerns are especially salient for this group because students tend to come from lowerincome families (Nuñez \& Cuccaro-Alamin, 1998). As a result, FGCS are more likely than their peers to work full or part-time jobs while in college (Bradbury \& Mather, 2009; Engle et al., 2006; Pratt et al., 2019), as previously mentioned. The study by Pratt et al. (2019) noted that a lack of finances could force withdrawal from class or college for more than $50 \%$ of FGCS. The burdens of a commitment to both work and school may be borne disproportionately by rural students, whose geographical isolation predicts lengthy commutes to physical campuses (Peterson et al., 2015) or else preference for remote educational opportunities in order to avoid a lengthy commute. Remote educational opportunities are likely to be of interest to FGCS of varied, and not just rural, backgrounds given time-management concerns of this population (Garriott \& Nisle, 2018). Yet Smith (2010), for instance, finds $40-80 \%$ of online students drop out of online courses, and Herbert (2006) finds that online courses have a 10-20\% higher failed retention rate (Bawa, 2016), potentially exacerbating problems of persistence.

When comparing FGCS to non-FGCS, Warburton et al. (2001) found that FGCS are more likely to attend part-time while working full-time, stop out or downward transfer, and are more likely to leave their institutions and never return. While the likelihood of these events was reduced in cases where FGCS took a more rigorous high-school curriculum, correlations were present in most situations, even when controlling for additional variables. In addition to a positive correlation with academic difficulties, FGCS status correlated with many other attributes that may decrease the likelihood of success. Such attributes include an increased need for remedial courses and lower grade 
point averages. First-generation college students also tend to enroll in less prestigious, two-year institutions and four-year comprehensive universities as opposed to private and research institutions (Warburton et al., 2001). Additionally, FGCS tend to choose less specific majors than their non-FGCS counterparts (Warburton et al., 2001).

Warburton et al. (2001) delivered insights into challenges faced by FGCS in the academy but further discussion of applicability is merited. Warburton et al. as well as Chen and Carroll (2005) provided useful aggregate data that correlates FGCS status to risk factors and academic outcomes. Darling and Smith (2007) provided a humanistic view of barriers to academic success by considering non-academic characteristics of FGCS, and the effects of multiple high-risk indicators. While the works provided much detail for faculty, advisors, and administrators, little is done to identify high-risk correlations insofar as they may be more relevant to urban, suburban, or rural settings. The level of generalizability implied by suggesting that campus programming should respond to aggregated data is questionable. Much like Darling and Smith (2007), Pratt et al. (2019) provided a personal view of the challenges encountered by some FGCS by bringing to the light the financial barriers faced by some along with the confidence factor that correlates with lack of academic preparedness.

Below, a review of literature exploring non-academic influences on FGCS adds much detail to the discussion of psychosocial attributes reported by Darling and Smith (2007). It is important that FGCS research transcend measurable objectives and quantitative correlations to provide actual illustrations and first-person accounts that give higher education educators and administrators clear examples of potential issues, especially those outside the academy. Stress and other emotional factors are rarely examined; however, the COVID-19 pandemic has brought the importance of addressing these issues to the fore. Educators and administrators will also find insights into root causes of attrition and poor academic performance valuable when designing programs to help FGCS meet their educational goals and supporting FGCS in these uncertain times.

\section{Non-Academic Influences}

One of the most salient themes of the FGCS research reviewed is that that FGCS are more vulnerable than other groups to experience non-academic hardships that inhibit success in the academy. Bradbury and Mather (2009), and Coffman (2011) provided insights into supporting FGCS by publishing needs, issues, and challenges captured in the students' own words. Coffman (2011) posited that challenges all students may face were exacerbated among 
FGCS by the addition of low educational aspirations, low familial support, a utilitarian view of college education, and a relatively higher need for strong social support. Coffman (2011) found many instances in which previous research was solidified through interviews and dialog. Bradbury and Mather (2009) highlighted similar obstacles faced by FGCS in Appalachian Ohio.

In their localized study of FGCS, Bradbury and Mather (2009) described a "pull from home" $(2009$, p. 264) that distracted FGCS from their academic studies and integration into campus life. Participants shared concerns of successfully making an "academic adjustment" (Bradbury \& Mather, 2009, p. 268), noting that academic engagement, relationships with faculty, and motivation to attend college all played critical roles in persisting. The students interviewed also shared a needed sense of "belonging" in addition to purely academic relationships (Bradbury \& Mather, 2009, p. 270). Tinto (1988) also noted the importance of integration when discussing factors influencing persistence. Lastly, the FGCS interviewed by Bradbury and Mather shared the ominous concern of "financial realties" $(2009$, p. 272) that served as a constant stressor concerning future debt, college funding, and the intimidating process of using financial aid.

Coffman (2011) described key influences that can serve as focal points for administrators and faculty supporting FGCS. A thorough understanding of these social factors allows for more effective pedagogy and applicable programming. The seven social influences described by Coffman span race, educational aspirations, poor choices, social class, academic preparation, strong social network, and upward social mobility and meaningful work (social mobility and meaningful work are condensed to a single influence). Walpole (as cited in Coffman, 2011) provided insights that highlighted the inability of race to be independently studied as FGCS represent many high-risk populations. Knowledge of this phenomenon is critical in that, while race may play a significant role in constructing views about higher education, assigning influential characteristics based solely on race (as opposed to race and an FGCS status) could lead to misguided programing and ineffective interventions. Take for example, the data that demonstrates that FGCS are more likely to be minority, low-income and women with children (Ward et al., 2012). The harm with conflating these groups comes when the disadvantages of FGCS appear to be disadvantages experienced by all groups. Overgeneralizing ignores how FGCS experience additional or differing challenges. Davis (2010), argued that this approach had not served these students very well.

It is important to remain cognizant that FGCS are by many definitions the first person in their family to attend any form of higher education. 
Imagine, then, the role family background plays in constructing a FGCS's view of the college experience. Previous research (Davis, 2010; Peteet et al., 2015; Ward et al., 2012) suggests that FGCS have a particularly difficult time finding confidence in their identity as college students, and that exacerbates the difficulties that they face as students.

Imposter phenomenon has been tied to FGCS both theoretically (Davis, 2010) and empirically (Peteet et al., 2015). Coffman (2011) provided that the immediate family's lack of education may perpetuate a decreased appreciation for higher education, thus contributing to lower educational aspiration. The lack of social capital transmitted from family and friends contributes to a lack of awareness of the extent to which lower standardized scores and GPA might affect their academic outcomes (Vargas, 2004). As discussed, Bradbury and Mather (2009) and Coffman (2011) did much to describe non-academic challenges faced by FGCS through narratives and first-person accounts. However, further insights can be obtained by reviewing findings correlating similar FGCS attributes with barriers to academic success.

Garriott and Nisle (2018) presented a study that examined stress, coping and perceived academic goal progression among FGCS. Stress was significantly related to institutional support. Stresses included living away from home for the first time, adjusting to the rigor of college-level classes, developing friendships, and time management. Garriott and Nisle (2018) acknowledged that FGCS face unique challenges specific to their socioeconomic status. The study suggests that FGCS may experience greater stressors compared to their peers. In an age of global crises, faculty, staff, and administrators must craft more efficient outreach to their FGCS to ensure better support given their trying circumstances.

Pascarella, Peirson, Wolniak, and Terenzini (2004) did much to further educators' knowledge of this high-risk group in a landmark study quantifying effects of academic and non-academic challenges of FGCS in 18 US universities. In a statement recapitulating a review of FGCS data, Pascarella et al. suggested that FGCS face heightened barriers compared to non-FGCS in socioeconomic status, diminished familial support, lower educational aspirations, and deficient knowledge of university functions. This report also stated that FGCS often have "substantial cultural as well as social and academic transitions" in addition to the "anxieties, dislocations, and difficulties" (2004, p. 250) many college students encounter. Pascarella et al. correlated challenges above with the inability to live on campus, participate in extra- and co-curricular activities, engage academically, and otherwise fully participate in educational pursuits. This finding is notable, as these 
activities were found to increase satisfaction, educational aspirations, and academic confidence. Students attending a post-secondary institution different from settings they are used to, e.g., rural students in an urban university setting, may experience this detachment more noticeably (Heinisch, 2017). Identifying and ameliorating the academic and psychosocial challenges that inhibit FGCS from engaging in activities that are most beneficial to their success should be a target of programs to support retaining this growing group.

Bradbury and Mather (2006), Coffman (2011), and Pascarella et al. (2004) provided qualitative data that illuminates the statistics reported in outcomes-based studies. The literature covering non-academic inhibitors of FGCS success allows faculty and administrators to regain an appreciation for each individual behind the outcomes aggregated and studied en masse. Statistical figures, culminating outcomes, and numerical data are well augmented by individual stories and first-person accounts that allow educators to refocus on individual FGCS success through empathy and personalized efforts. However, faculty, administrators, and support staff must appreciate varying challenges students in certain settings are more likely to face and build support and retention programming addresses those challenges. One must still be careful to appreciate specific challenges of each FGCS, but scalable programming will be more effective if informed by more accurate, setting-specific studies.

\section{IMPLICATIONS FOR FUTURE RESEARCH}

The aforementioned data suggests FGCS are challenged particularly by academic preparation, low levels of persistence, and non-academic barriers. Although useful for some purposes, the ability of aggregate data on FGCS to provide effective guidance in particular, concrete settings is questionable. Research has shown that urban, suburban, and rural students often have setting-specific academic inhibitors and psychosocial concerns that do not align with national trends. Aggregate data may include information from urban, suburban, and rural settings, but does not necessarily provide an accurate depiction of FGCS in any single environment. Chen and Carroll (2005), for example, noted that his study conflicted with previous research on FGCS. Large, wide-scale studies have diminished applicability to any single setting to the extent of the study's geographical breadth.

Several studies reviewed took steps to ameliorate overgeneralization and increase applicability with region-specific studies. Engle et al. (2006), for example, furthered the applicability of FGCS data by restricting their study to FGCS in the state of Texas. However, this localization to the state level is not 
without limitations. Consider the varying environmental settings encompassed by the second largest state in the U.S., and the potentially misleading implications of pooling focus group responses from, for example, the highly rural Kingsville, TX or the border town of Edinburg, TX, alongside responses from urban centers like Houston or Dallas, TX. As previously mentioned, would it be advisable for a community college in urban Fort Worth, Texas, to implement the same responsive programming in support of FGCS as a comprehensive university that enrolls a large percentage of affluent students from suburban populations? How should these interventions differ from the supporting efforts of educators in rural settings, or settings where a large population of students speaks English as a second language? Can the accuracy and applicability of supportive efforts be increased by further appreciating the differing backgrounds, needs, and recourses of students from varying settings? Future research must appreciate the known differences in the attributes, experiences, and outcomes of FGCS in varying settings to more accurately inform efforts aimed at supporting this group.

What appears to be needed in FGCS research is a common denominator that will provide educators with characteristics and challenges correlated with FGCS in the setting in which their institution resides. For instance, Chen and Carroll's (2005) findings suggest that secondary curricula rigor alone is insufficient to promote post-secondary success. Research on what additional factor(s) make secondary rigor have predictive value for postsecondary success is needed. Additionally, setting-specific stratification would serve to refine challenges and trends highlighted in aggregate findings. Refining data to urban, suburban, and rural settings would increase the transferability of findings by allowing institutions in similar settings to study programs successfully supporting FGCS in the academy, alongside cognizance of aggregate trends.

Setting-specific studies would benefit faculty and administrators by providing details of relevant, particular student concerns that may be lost in aggregate research. In addition, research contrasting urban, suburban, and rural FGCS characteristics would not only provide details of setting-specific barriers to academic success, but increase transferability in that multiple urban, suburban, and rural settings would benefit from knowledge of settingspecific issues. This level of detail and transferability is not often found in FGCS research and could serve to improve the efficacy of educators in every setting in supporting FGCS as disadvantaged individuals navigating the academic and social landscapes of urban, suburban, and rural institutions. 


\section{CONCLUSION}

We, as educators, have a responsibility to understand the potential challenges faced by FGCS and create reciprocal supportive programs for our students. Failure to effectively support FGCS could result not only in economic issues for colleges and universities, but economic hardships and mental duress for unsuccessful FGCS as individuals. Our study highlights three central findings in FGCS research, namely the presence of unique difficulties in degree of academic preparation, persistence, and non-academic barriers. We pay careful attention to setting-specific variables insofar as the limited data allow, and consider more careful attention to urban, suburban, and rural to be a primary locus of future FGCS research.

This is a critical time in U.S. higher education as institutions face tough budget decisions while juggling the more prominent needs of FGCS. Greater cognizance of aggregate FGCS trends, and attention to settingspecific variables, will help educators discharge their responsibilities to this vulnerable population and help promote equity within their institutions and in society more broadly. Failure to support FGCS not only deprives this population of an effective means for upward social mobility, it also furthers hardships at the national level in the form of increased default rates on student loans (Perna et al., 2017), particularly dangerous given the present $\$ 1.5$ trillion in outstanding loans in the US (Friedman, 2019). A failure here also means fewer skilled workers in the workforce (Bowen et al., 2011) and further negative impacts of social classes predicated on socioeconomic status (Bowen et al., 2005). With these potential ramifications in mind, literature must be periodically reviewed to ensure faculty and advisors are provided with research relevant to FGCS's needs to inform effective retention programming in colleges and universities. Although more research into this vulnerable population is merited, this study's comprehensive literature review at least highlights the central trends discernable from 2000-2020, and is likewise an excellent starting point for educators seeking insight into how best to assist first generation college students.

\section{REFERENCES}

Atherton, M. C. (2014). Academic preparedness of first-generation college students: Different perspectives. Journal of College Student Development, 55(8), 824-829. http://doi.org/10.1353/csd.2014.0081

Aucejo, E. M., French, J., Ugalde Araya, M. P., \& Zafar, B. (2020). The impact of COVID-19 on student experiences and expectations: Evidence from a survey. Journal of Public Economics, 191(2020), 104271. https://doi.org/10.1016/j.jpubeco.2020.104271 
Azmitia, M., Sumabat-Estrada, G., Cheong, Y., \& Covarrubias, R. (2018). "Dropping Out is Not an Option": How educationally resilient first-generation students see the future. New Directions for Child and Adolescent Development, 2018(160), 89-100. https://doi.org/10.1002/cad.20240

Bawa, P. (2016). Retention in online courses: Exploring issues and solutions-A literature review. SAGE Open, 6(1), 2158244015621777. https://doi.org/10.1177/2158244015621777

Bowen, W. G., Chingos, M. M., \& McPherson, M. S. (2011). Crossing the finish line: Completing college at America's public universities. Princeton University Press.

Bowen, W. G., Kurzweil, M. A., Tobin, E. M., Pichler, S. C., Hall, M., \& Ryan, A. (2005). Equity and excellence in American higher education. University of Virginia Press.

Bradbury, B. L., \& Mather, P. C. (2009). The Integration of first-year, first-generation college students from Ohio Appalachia. NASPA Journal, 46(2), 258-281. https://doi.org/10.2202/1949-6605.6041

Byun, S., Meece, J. L., Irvin, M. J., \& Hutchins, B. C. (2012). The role of social capital in educational aspirations of rural youth*. Rural Sociology, 77(3), 355-379. https://doi.org/10.1111/j.1549-0831.2012.00086.x

Cataldi, E. F., Bennett, C. T., \& Chen, X. (2018). First-generation students: College access, persistence, and postbachelor's outcomes. National Center for Education Statistics. https://eric.ed.gov/?id=ED580935

Chen, X., \& Carroll, C. D. (2005). First-generation students in postsecondary education: A look at their college transcripts. National Center for Education Statistics. https://eric.ed.gov/?id=ED485756

Clark, M. H., \& Cundiff, N. L. (2011). Assessing the effectiveness of a college freshman seminar using propensity score adjustments. Research in Higher Education, 52(6), 616-639. https://doi.org/10.1007/s11162-010-9208-x

Clark, M. R. (2006). Succeeding in the city: Challenges and best practices on urban commuter campuses. About Campus, 11(3), 2-8. https://doi.org/10.1002/abc.166

Coffman, S. (2011). A social constructionist view of issues confronting firstgeneration college students. New Directions for Teaching and Learning, 2011(127), 81-90. https://doi.org/10.1002/t1.459

Cooper, H. M. (1985). A Taxonomy of Literature Reviews. https://eric.ed.gov/?id=ED254541

Darling, R. A., \& Scandlyn Smith, M. (2007). First-generation college students: Firstyear challenges. In M. S. Hunter, B. McCalla-Wriggins, \& E. R. White (Eds.), Academic advising: New insights for teaching and learning in the first year (pp. 203-211). National Resource Center for The First-Year Experience and Students in Transition.

Davis, J. (2010). The First-Generation student experience: Implications for campus practice, and strategies for improving persistence and success. Stylus Publishing. 
Engle, J., Bermeo, A., \& O'Brien, C. (2006). Straight from the source: What works for first-generation college students. Pell Institute for the Study of Opportunity in Higher Education. https://eric.ed.gov/?id=ED501693

Friedman, Z. (2019, February 25). Student loan debt statistics in 2019: A \$1.5 trillion crisis.

Forbes.

https://www.forbes.com/sites/zackfriedman/2019/02/25/student-loan-debtstatistics-2019/

Garriott, P. O., \& Nisle, S. (2018). Stress, coping, and perceived academic goal progress in first-generation college students: The role of institutional supports. Journal of Diversity in Higher Education, 11(4), 436-450. https://doi.org/10.1037/dhe0000068

Handwerk, P., Tognatta, N., Coley, R. J., \& Gitomer, D. H. (2008). Access to success: Patterns of advanced placement participation in U.S. high schools. Educational Testing Service. https://eric.ed.gov/?id=ED505556

Heinisch, B. P. (2017). Small fish out of water: Rural first-generation student experience at a large university. Journal of College Orientation, Transition, and Retention, 24(1), Article 1. https://doi.org/10.24926/jcotr.v24i1.2904

Herbert, M. (2006). Staying the course: A study in online student satisfaction and retention. Online Journal of Distance Learning Administration, 9(4). https://www.westga.edu/ distance/ojdla/winter94/herbert94.htm

Langford, J., \& Clance, P. R. (1993). The imposter phenomenon: Recent research findings regarding dynamics, personality and family patterns and their implications for treatment. Psychotherapy: Theory, Research, Practice, Training, 30(3), 495-501. https://doi.org/10.1037/0033-3204.30.3.495

Nuñez, A.-M., \& Cuccaro-Alamin, S. (1998, June 10). First-generation students: Undergraduates whose parents never enrolled in postsecondary education. National Center for Education Statistics. https://nces.ed.gov/pubsearch/pubsinfo.asp?pubid=98082

O'Keeffe, P. (2013). A sense of belonging: Improving student retention. College Student Journal, 47(4), 605-613. http://www.projectinnovation.biz/csj.html

Parks-Yancy, R., \& Cooley, D. (2018). Who gets the job? First-generation college students' perceptions of employer screening methods. Journal of Education for Business, 93(1), 1-10. https://doi.org/10.1080/08832323.2017.1409691

Pascarella, E. T., Pierson, C. T., Wolniak, G. C., \& Terenzini, P. T. (2004). Firstgeneration college students. The Journal of Higher Education, 75(3), 249284. https://doi.org/10.1080/00221546.2004.11772256

Perna, L., Kvaal, J., \& Ruiz, R. (2017). An updated look at student loan debt repayment and default. Wharton Public Policy Initiative Issue Briefs, 5(06). https://repository.upenn.edu/pennwhartonppi/46

Peteet, B. J., Montgomery, L., \& Weekes, J. C. (2015). Predictors of imposter phenomenon among talented ethnic minority undergraduate students. The Journal of Negro Education, 84(2), 175-186. https://doi.org/10.7709/jnegroeducation.84.2.0175 
Peterson, B., Bornemann, G., Lydon, C., \& West, K. (2015). Rural students in washington state: stem as a strategy for building rigor, postsecondary aspirations, and relevant career opportunities. Peabody Journal of Education, 90(2), 280-293. https://doi.org/10.1080/0161956X.2015.1022397

Pratt, I. S., Harwood, H. B., Cavazos, J. T., \& Ditzfeld, C. P. (2019). Should I stay or should i go? retention in first-generation college students. Journal of College Student Retention: Research, Theory \& Practice, 21(1), 105-118. https://doi.org/10.1177/1521025117690868

Radford, A. W., Cominole, M., \& Skomsvold, P. (2015). Demographic and enrollment characteristics of nontraditional undergraduates: 2011-12. web tables. NCES 2015-025. National Center for Education Statistics. https://eric.ed.gov/?id=ED581707

Radunzel, J. (2018). Examining retention and transfer in relation to incoming student data for first-generation and continuing-generation students: What differences exist? Journal of College Student Retention: Research, Theory \& $\quad$ Practice, 1521025118813516. https://doi.org/10.1177/1521025118813516

Reid, M. J., \& Moore, J. L. (2008). College readiness and academic preparation for postsecondary education: Oral histories of first-generation urban college students. Urban Education, 43(2), 240-261. https://doi.org/10.1177/0042085907312346

Ryan, M. P., \& Glenn, P. A. (2004). What do first-year students need most: Learning strategies instruction or academic socialization? Journal of College Reading and Learning, 34(2), 4-28. https://doi.org/10.1080/10790195.2004.10850159

Smith, B. G. (2010). E-learning technologies: A comparative study of adult learners enrolled on blended and online campuses engaging in a virtual classroom (No. 3413143). [Doctoral dissertation, Capella University]. ProQuest Dissertations \& Theses A\&I. https://www.proquest.com/dissertations-theses/e-learning-technologiescomparative-study-adult/docview/746605945/se-2?accountid=28333

Tieken, M. C. (2016). College talk and the rural economy: Shaping the educational aspirations of rural, first-generation students. Peabody Journal of Education, 91(2), 203-223. https://doi.org/10.1080/0161956X.2016.1151741

Tinto, V. (1988). Stages of student departure: Reflections on the longitudinal character of student leaving. The Journal of Higher Education, 59(4), 438455. https://doi.org/10.1080/00221546.1988.11780199

Vargas, J. H. (2004). College knowledge addressing information barriers to college. The Education Resources Institute (TERI).

Warburton, E. C., Bugarin, R., \& Nuñez, A.-M. (2001). Bridging the Gap: Academic Preparation and Postsecondary Success of First-Generation Students 
(NCES 2001-153). National Center for Education Statistics. https://nces.ed.gov/pubsearch/pubsinfo.asp?pubid=2001153

Ward, L., Siegel, M. J., \& Davenport, Z. (2012). First-generation college students: Understanding and improving the experience from recruitment to commencement. Jossey-Bass.

Weissman, S. (2020, April 19). The underrepresented, underprivileged hit hard by coronavirus-related campus closures. Diverse: Issues in Higher Education. https://diverseeducation.com/article/173382/

Woods, C. S., Park, T., Hu, S., \& Betrand Jones, T. (2018). How high school coursework predicts introductory college-level course success. Community College Review, 46(2), 176-196. https://doi.org/10.1177/0091552118759419

FRANCESKA C. JONES, MNO, is a doctoral candidate at Morgan State University in the Community College Leadership program, an adjunct professor, and entrepreneur. Her dissertation research centers on community colleges alumni giving. She has expertise in student support services and retention. Email: frjon1@ morgan.edu

THOMAS J. EVELAND, Ph.D., is an assistant professor and Director of Graduate Programs in Business at Ohio Dominican University. His research focuses on various business topics and first-generation college student success.

BRIAN BESONG, Ph.D., is an associate professor of philosophy at Saint Francis University. His research focuses on ethics and moral knowledge.

Email: bbesong@ francis.edu.

Manuscript submitted: October 15, 2020

Manuscript revised: January 14, 2021, June 7, 2021 Accepted for publication: October 28, 2021 